\title{
O Amálgama floresta e agricultura na Reserva Extrativista Arióca Pruanã
}

\section{The amalgam forests and agriculture in the Arióca Pruanã Extractivist Reserve}

Amintas Lopes da Silva Junior - Mestre em Agriculturas Familiares e Desenvolvimento Sustentável (UFPA). Pesquisador bolsista do Conselho Nacional de Desenvolvimento Científico e Tecnológico na Empresa Brasileira de Pesquisa Agropecuária Amazônia Oriental, Belém, PA. E-mail: amintas. silvajr@gmail.com

Sônia Maria Simões Barbosa Magalhães Santos - Doutora em Antropologia (UFPA) e em Sociologia pela Université Paris 13, docente e pesquisadora do Programa de Pós-Graduação em Agriculturas Amazônicas, Núcleo de Ciências Agrárias e Desenvolvimento Rural, da Universidade Federal do Pará, Belém, PA. E-mail: smag@ufpa.br

Maria das Graças Pires Sablayrolles - Doutora em Biologia Vegetal pela (UFPE), docente e pesquisadora do Programa de Pós-Graduação em Agriculturas Amazônicas, Núcleo de Ciências Agrárias e Desenvolvimento Rural, da Universidade Federal do Pará, Belém, PA. E-mail: mpires@ufpa.br

\section{Resumo}

O presente estudo aborda o papel dos sítios e terreiros enquanto interface entre agricultura e extrativismo na Reserva Extrativista Arióca Pruanã, em Oeiras do Pará. A agricultura depende da floresta e a reconfigura em capoeiras e sítios, assim como a floresta se insinua nos terreiros à medida que espécies vegetais silvestres são aí introduzidas por mãos humanas. O resultado deste manejo é o agroflorestamento da paisagem, face visível do amálgama entre agricultura e floresta, base da reprodução da vida ribeirinha.

\section{Palavras-chave}

Agricultura. Florestas. Terreiros. Reserva Extrativista.

\begin{abstract}
The present study addresses the role of orchards and yards as interface between agriculture and extractivism in the Arióca Pruanã Extractivist Reserve, in the city of Oeiras, Pará state, Brazil. The agriculture depends on the forest and reconfigures it into secondary forests and orchards, as well as the forest insinuates itself into the yards as the wild plant species are therein introduced by human hands. The result of this management is the agroforestry in the landscape, visible face of the amalgam between agriculture and forest, and reproduction basis of the riparian lifestyle.
\end{abstract}

\section{Keywords}

Agriculture. Forests. Yards. Extractivist Reserve. 


\section{INTRODUÇÃO}

A Reserva Extrativista Arióca Pruanã (REAP) está localizada no município de Oeiras do Pará, na microrregião de Cametá, abrangendo 83.445,125 hectares, que perfazem 21,66 \% da área municipal. O presente estudo foi realizado na vila de Melancial, ao extremo sul da REAP, onde residem 40 famílias de um total de 520, distribuídas por toda a área da referida unidade de conservação.

Os moradores de Melancial vivem ao modo das populações ribeirinhas que há séculos moldam seus estilos de vida e culturas às margens dos grandes e pequenos rios da região amazônica (FRAXE; PEREIRA; WITKOSKI, 2007). Adams, Murrieta e Neves (2006) afirmam que estes modos de vida ribeirinhos são diversos e não especializados. Em consonância, a descrição dos sistemas de produção amazônicos empreendida no âmbito do extrativismo, por autores como Lescure e Pinton (1996) e Lescure, Pinton e Emperaire (1996), incluem atividades tão diversas quanto agricultura, pesca, caça, coleta e criação de animais, consideradas indissociáveis entre si. Esta diversificação tem assegurado a manutenção da base de recursos explorada pelos ribeirinhos, apesar da condição de invisibilidade econômica e social alimentada, em parte, pelas formas inadequadas através das quais são interpretados os seus sistemas de produção e de reprodução (BRONDÍZIO, 2006).

Em meio à diversidade de estratégias produtivas e reprodutivas adotadas por essas populações, o engajamento em distintas formas de extrativismo e agricultura em unidades familiares é, à maneira proposta por Almeida (2008), imprescindível para a população ribeirinha que habita a REAP, a ponto destas atividades se constituírem em elementos de afirmação de sua identidade. Este trabalho pretende demonstrar que há na REAP um amálgama entre extrativismo e agricultura, esta última, embora talvez não tão obviamente quanto o primeiro, é também plenamente incorporada à vida na floresta, dependente e reconfigurante desta. Essa estreita relação possui antecedentes históricos que remontam aos milênios nos quais a agricultura de corte e queima, também denominada coivara, tem sido praticada nas regiões tropicais do planeta (PEDROSO JÚNIOR; MURRIETA; ADAMS, 2008).

A pesquisa é de cunho qualitativo, tendo sido utilizadas como técnicas observação participante, entrevistas semiestruturadas, caminhadas transversais e elaboração de calendário sazonal. Além disso, foi coletado material botânico para identificação no Herbário IAN da EMBRAPA Amazônia Oriental. As caminhadas transversais consistiram em percorrer os caminhos cotidianos dos moradores, na companhia destes, observando os sucessivos ecossistemas e agroecossistemas

Novos Cadernos NAEA, v. 16, n. 1, Suplemento, p. 181-201, jun. 2013 
e indagando sobre o histórico de exploração produtiva (PEREIRA; LITTLE, 2000). O calendário sazonal foi elaborado a partir da listagem de atividades produtivas, eventos sociais, fenômenos ambientais e recursos naturais disponíveis no decorrer do ano.

\section{EXTRATIVISMO E AGRICULTURA}

A discussão sobre o extrativismo inclui desde a crença na tendência inequívoca à domesticação ou substituição de produtos extrativos por análogos sintéticos (HOMMA, 1996), até a discordância com relação a esta prática se constituir em coleta limitada aos estoques naturais (RÊGO, 1999). Para o segundo autor, não se pode admitir como objeto do extrativismo uma natureza intocada, uma vez que todo uso humano da biota implica em alterações na cobertura florestal e alguma forma de manejo dos ecossistemas é empreendida pelas populações humanas desde tempos remotos, posição sustentada por inúmeros trabalhos (ANDERSON; POSEY, 1985; POSEY, 1986; ANDERSON; POSEY, 1991; BALÉE, 1989; ADAMS, 1994; DIEGUES, 2008).

Em decorrência, Rêgo propõe a existência do que denomina neoextrativismo, que é a combinação das atividades extrativistas propriamente ditas com técnicas de cultivo, criação de animais e beneficiamento da produção, imersas em um ambiente social dominado pelo universo cultural singular das populações extrativistas, incluindo diversificação, consórcio de espécies, imitação da estrutura das florestas e uso de técnicas desenvolvidas a partir das práticas e saberes tradicionais relacionados aos ecossistemas regionais (REEGO, 1999).

Não obstante, Homma (1989; 1993; 1996; 2005a; 2005b; 2008) acredita que a domesticação implica no desaparecimento do extrativismo: para o autor, a agricultura o substitui. O exemplo da REAP aponta para o contrário, porque nesta unidade de conservação, a domesticação em curso nos quintais interioranos mencionada pelo autor (HOMMA, 2008) se dá em um contexto no qual agricultura e floresta não se distinguem com clareza: o extrativismo não se dá em áreas prístinas.

Além disso, há um entendimento de que o extrativismo praticado na região Amazônica, na maior parte dos casos, preserva a diversidade biológica e a capacidade de regeneração da floresta. O respeito aos limites biológicos de regeneração dos recursos, sem emprego de meios mecanizados na extração, altera pouco os ecossistemas florestais (BAHRI, 2000). A combinação da policultura de queimadas com outras atividades produtivas se constitui em uma forma de 
habitar as paisagens florestadas sem eliminá-las, que vem sendo desenvolvida por décadas ou mesmo por séculos pelas populações ribeirinhas (DRUMMOND, 1998). A partir desta perspectiva, Allegretti (1996) assume que a economia extrativa mantém a floresta em pé, porque esta é a base de sua sustentação.

Os efeitos da interferência humana sobre as florestas amazônicas provavelmente se fazem sentir desde tempos remotos, como consequência da horticultura indígena, para usar a expressão de Balée (1989), ou principalmente a partir do advento da agricultura, não obstante os impactos de outras atividades humanas que a antecederam, da forma como propõe Adams (1994). Embora os vestígios de antigas perturbações humanas sejam sutis, eles se exemplificam por toda a Amazônia na presença de espécies fora de sua área de ocorrência natural; na dominância de espécies indicadoras de perturbação tais como palmeiras, bambus ou cipós; nas ilhas de cerrado e nos antigos castanhais (BALÉE, 1989).

Em consonância, Adams (1994), propõe que extensas áreas de florestas consideradas primárias abrigam, na realidade, florestas secundárias que resultaram de um manejo complexo perpetrado por populações ancestrais. É de se esperar que as paisagens decorrentes de tal manejo sejam indistinguíveis de hipotéticas florestas virgens, o que pode ter contribuído para a disseminação do mito prístino desmentido por Denevan (1992).

Referindo-se às práticas agrícolas dos Kayapó, Anderson e Posey (1991) afirmam que o modo como os índios alteram a estrutura de suas roças ao longo do tempo parece seguir um modelo de sucessão similar ao natural. Concomitantemente, Adams (1994) considera a agricultura de coivara ainda intensamente praticada nos trópicos, um exemplo de sistema policultural complexo. Para a autora, "as espécies utilizadas no cultivo substituem espécies selvagens com nichos ecológicos semelhantes, simulando a estrutura e função do ecossistema natural" (ADAMS, 1994, p. 5).

A agricultura itinerante praticada pelos Kayapó, da forma como descrita por Posey (1986), envolve a formação de capoeiras que, nas palavras do autor, são tudo, menos campos de cultivo abandonados. A partir do estágio inicial de roça de tubérculos, espécies úteis cultivadas e espontâneas continuam sendo colhidas indefinidamente nas capoeiras em sucessão. Estas áreas passam por uma espécie de estágio de roça residual com pomar, quando cumprem as funções de campo de caça e de provimento de itens como iscas para pesca, tinturas, repelentes, material de construção, fibras e principalmente medicamentos, até que finalmente a floresta alta se restabeleça (POSEY, 1986).

Em consonância, Anderson e Posey (1985) já descreviam alguns anos antes o manejo indígena praticado pelos Kayapó como uma sucessão de plantios de

Novos Cadernos NAEA, v. 16, n. 1, Suplemento, p. 181-201, jun. 2013 
ciclos de vida cada vez mais longos, até o momento em que os índios introduzem espécies florestais de grande porte, tais como a castanha-do-pará. Este exemplo evoca a proposição de Adams (1994), para quem a coexistência de populações humanas com as florestas proporcionou um acúmulo de conhecimento que permitiu a intervenção agrícola nestes ecossistemas de forma não destrutiva, e em alguns casos até benéfica, funcionando como fonte de variabilidade.

É conveniente sublinhar que a interferência humana nos estágios sucessionais da regeneração, através do enriquecimento com espécies úteis, a exemplo do que fazem os Kayapó (ANDERSON; POSEY, 1985; 1991; POSEY, 1986), incide justamente sobre a cobertura vegetal já resultante de alterações antropogênicas. Contribuindo para tornar ainda menos evidente a já tênue distinção entre extrativismo e agricultura que os exemplos citados denotam, outros estudos também dão conta das consequências genéticas de práticas indígenas sobre espécies frutíferas silvestres (KERR; CLEMENT, 1980; KERR, 1997). Esse agroflorestamento da paisagem dá a tônica de um manejo no qual "nem sempre é fácil distinguir plantas silvestres de cultivadas, uma vez que existem estágios intermediários” (LÉVI-STRAUSS, 1997, p. 20).

Enfim, os agroecossistemas típicos da REAP, constituídos por roças de ciclo curto implementadas a partir da queima de pequenas porções de mata, seguida de pousio, demandam práticas de manejo da paisagem que alternam, continuamente, perturbação e regeneração da cobertura vegetal. No âmbito da discussão que se pretende desenvolver aqui, a capoeira, resultado do pousio característico da agricultura itinerante, pode ser compreendida como o primeiro ponto de interseção entre ambientes cultivados e silvestres, entre agricultura e florestas. Entretanto, se as capoeiras se constituem no substrato privilegiado para a implantação de sítios, ambiciona-se sustentar que os quintais das casas, denominados localmente de terreiros, também abrigam em seu seio amostras da floresta.

\section{AGROBIODIVERSIDADE}

A agrobiodiversidade é um conceito ainda em construção. Produto da intervenção criativa do homem sobre os ecossistemas em sua contínua interação com o ambiente natural, a agrobiodiversidade engloba todos os elementos que interagem na produção agrícola (SANTILLI, 2009). Os três níveis de complexidade que caracterizam a biodiversidade também se organizam hierarquicamente de forma similar na agrobiodiversidade: diversidade dentro de espécies, entre espécies e de ecossistemas (MACHADO; SANTILLI; MAGALHÃES, 2008). 
Desta forma, não há maiores controvérsias quanto à inclusão no conceito, de espécies animais domesticadas, espécies vegetais cultivadas e seus parentes silvestres, plantas espontâneas em cultivos, parasitas, predadores, patógenos, polinizadores, simbiontes, e da diversidade genética a eles associada, além dos ambientes cultivados propriamente ditos e áreas de pastagens naturais. Não obstante, as práticas de manejo, cultivo, criação e seleção de espécies, desenvolvidas e compartilhadas por agricultores e criadores de todo o mundo ao longo dos últimos dez a 12 mil anos, foram responsáveis, em grande parte, pela enorme diversidade existente de plantas cultivadas, animais domésticos e de agroecossistemas que os abrigam (SANTILLI, 2009).

De fato, o humano, ou melhor, as sociedades e culturas são a chave para a diferenciação do que é agrobiodiversidade em meio à biodiversidade (STELLA; KAGEYAMA; NODARI, 2006). Em decorrência, o conjunto formado pela diversidade biológica representada por espécies, variedades, populações e ecossistemas relacionados aos sistemas de cultivo e pelos conhecimentos relacionados ao manejo destas espécies e ecossistemas é indissociável. Não se pode prescindir da atenção às intervenções humanas em quaisquer tentativas de se compreender a agrobiodiversidade, aí incluídas as diferentes práticas de manejo dos agroecossistemas, os saberes e conhecimentos tradicionais relacionados às plantas, ao solo, ao clima, ao uso culinário, às festividades e cerimônias religiosas (MACHADO; SANTILLI; MAGALHÃES, 2008). Neste tocante, a ampla diversidade de contextos, processos e práticas culturais e socioeconômicas que incidem sobre os componentes biológicos, ecológicos e agrícolas da agrobiodiversidade não deve ser ignorada em detrimento destes (SANTILLI, 2009).

Não sem razão, um dos adendos à Convenção sobre Diversidade Biológica (CDB), a Decisão V/5, adotada por ocasião da $5^{\circ}$ Conferência das Partes da CDB, realizada em Nairóbi, entre 15 e 26 de maio de 2000, inclui na definição de agrobiodiversidade todos os componentes da biodiversidade que têm relevância para a agricultura e a alimentação (SANTILLI, 2009). A partir desta acepção, espécies vegetais silvestres coletadas para fins alimentícios são, inequivocamente, componentes da agrobiodiversidade.

Em consonância, a FAO considera a agrobiodiversidade um conjunto que inclui, além daqueles recursos que compõem a fração cultivada da paisagem: os recursos não domesticados (selvagens) dos campos, florestas, extensões de terra e ecossistemas aquáticos incluindo produtos das árvores, peixes e animais selvagens capturados para alimentação; e mesmo espécies não colhidas, desde que

Novos Cadernos NAEA, v. 16, n. 1, Suplemento, p. 181-201, jun. 2013 
ocorrentes nos ambientes mais amplos que apoiam de alguma forma a produção de alimentos nos ecossistemas cultivados (FAO, 2005).

Desta maneira, a agrobiodiversidade pode ser compreendida como a parcela da biodiversidade que apresenta fortes relações com as sociedades e culturas, representada por um conjunto de organismos e ecossistemas que podem ser domesticados, semidomesticados, cultivados ou apenas manejados pelo homem, assim como as plantas medicinais e aromáticas, as variedades crioulas, os sistemas agroflorestais, e o manejo agroextrativista de recursos nativos. (STELLA; KAGEYAMA; NODARI, 2006).

Propomo-nos a argumentar, então, que: a agrobiodiversidade gerida por populações como aquela que habita a área da REAP inclui, entre outros componentes, a diversidade vegetal silvestre; e as práticas produtivas agroextrativistas remetem a uma íntima relação entre as florestas e a agricultura na Amazônia, o que torna difícil distinguir entre o que é silvestre e cultivado.

Diante do exposto, sugere-se que a adequada apreciação das discussões que vêm sendo empreendidas acerca do extrativismo na Amazônia, só se torna possível a partir da constatação prévia de que as populações extrativistas da região forjam um amálgama entre agricultura e floresta, do qual resulta, em boa parte, a agrobiodiversidade que manejam.

\section{UM CALENDÁRIO COMPLEXO}

O foco do presente estudo é explicitar o amálgama existente entre agricultura e florestas, formações vegetais com as quais as pessoas possuem uma história em comum e que também se constituem, à maneira dos plantios, em fornecedoras de espécies úteis, a partir da experiência dos moradores da vila de Melancial, na REAP.

Em Melancial, espécies vegetais silvestres de uso alimentício são todas produtoras de frutos comestíveis, as "frutas do mato". Entretanto, estas espécies podem ser encontradas em condições distintas daquela silvestre inicial; e entender como se dá esse fenômeno somente é possível dentro de um contexto mais amplo, no qual as imbricações entre natureza e cultura se evidenciam a cada momento na rotina das famílias.

A abertura para o mundo, típica de uma população como a que habita há décadas as margens do Oeiras, é o que permite sua reprodução: seu modo de vida tende à não especialização das atividades, embora o nível de detalhamento das informações necessárias ao exercício de cada uma delas seja elevado. Entre 
o generalismo e a minúcia, os saberes que as pessoas detêm vão muito além daqueles relacionados à fauna e à flora locais, mas englobam ainda aspectos do clima, dos solos, da topografia e da hidrografia, implicações das distintas fases lunares, comportamento de materiais e outras preciosidades, em um conjunto verdadeiramente enciclopédico, jamais desvinculado da prática, embora baseado em pressupostos compartilhados com o grupo social de seus detentores (CUNHA; ALMEIDA, 2002). Esse conhecimento somente se torna inteligível se os saberes que o constituem não são apartados uns dos outros, de forma que todas as atividades que subsidiam se combinam em um calendário complexo.

As águas das chuvas que facilitam ou dificultam o transporte e escasseiam ou abundam o pescado, à medida que fazem correr mais ou menos caudalosos os rios e os igarapés, demandam atenção especial quando encharcam o solo destinado à produção agrícola. Neste momento, os tubérculos da mandioca, mesmo se já graúdos, não estarão bons para o fabrico da farinha, assim como a melhor macaxeira não se colhe nessa época e a mandiucaba (Manihot esculenta Crantz), o mais sensato é deixar estiar para arrancar.

A perspicácia na análise de fatores climáticos é determinante para que a implantação do roçado chegue a bom termo: um determinado intervalo de tempo deve ser observado entre a derrubada e a queima. Esta última, por sua vez, somente será bem-sucedida se não houver chuva, que, entretanto, é imprescindível no momento do plantio das manivas.

Ainda, a quantidade certa de chuva viabiliza a floração desta ou daquela árvore na mata, assim como impõe o aborto das flores ou a queda de frutos específicos, forragem para a fauna cinegética. A presença da carne de caça apreciada à mesa depende do desvendar destas sutilezas. Do contrário, é contar apenas com a sorte.

A fertilidade do solo determina o que se pode plantar: o milho (Zea mays L.) e o arroz (Oryza sativa L.) são mais "melindrosos" que a mandioca e, portanto, não podem ser replantados como esta no mesmo roçado, após a primeira colheita. É necessário derrubar e queimar a capoeira novamente para colher os grãos. Porém há mais o que observar: cada plantio e cada colheita exigem uma conjunção de fatores; os locais de pesca mudam no decorrer do ano, assim como os apetrechos e as espécies de peixes capturados; a análise criteriosa da topografia do terreno permite identificar o local adequado para plantar o açaizal ou o sítio com as fruteiras "do seco". No âmbito das práticas ribeirinhas, a leitura da paisagem e a análise das circunstâncias são empreendidas paralelamente.

Se nos quatro primeiros meses do ano, a floresta se apresenta dadivosa pela abundância de frutas comestíveis, no resto do ano, ainda se pode contar

Novos Cadernos NAEA, v. 16, n. 1, Suplemento, p. 181-201, jun. 2013 
com espécies de menor importância como o inajá (Maximiliana maripa (Aublet) Drude) ou o jatobá (Hymenaea courbaril L.), mas também com o indispensável tucumã-açu ou jabarana (Astrocaryum tucuma Martius) ou com o tão estimado açaî (Euterpe oleracea Mart.) que se planta. Impossível deixar de notar a semelhança com o quadro vivenciado pelos índios Urubu-Kaapor, descrito por Darcy Ribeiro (1974). Entretanto, os saberes acerca destas espécies não se restringem apenas àqueles necessários à efetivação da coleta. As floradas se converterão na próxima safra de frutas, mas antes disso, em proteína animal, porque a caça as consome. Além disso, se a agricultura altera a mata, esta também se insinua sobre a agricultura, na medida em que as frutas silvestres se tornam acessíveis nos sítios e quintais.

Os exemplos da diversidade e abrangência dos saberes ribeirinhos são profusos e não cabe aqui continuar a enumerá-los. Basta lembrar que eles incluem ainda uma enorme gama de práticas sociais tais como a reciprocidade, as festividades, a religiosidade e eventos esportivos, entre outras. Em Melancial, as atividades das famílias e os fatores que as influenciam se coadunam em um calendário complexo, cujo entendimento somente é possível se todo o conjunto for levado em conta.

\subsection{A agricultura que se confunde com a floresta}

Existem dois tipos básicos de sistemas de produção agrícola nas reservas, que são as roças e os sítios. Roça ou roçado é a denominação local, embora recorrente em toda a Amazônia e comum em outras regiões do país, para o cultivo da mandioca, nitidamente aquele de maior expressão na REAP. As áreas de roçado provêm grande quantidade de tubérculos que são a matéria-prima para a produção do principal item comercializado pelos agricultores da referida unidade de conservação: a farinha. Não obstante, a mandioca não é a única espécie presente nos roçados de Melancial, onde também são plantados os já citados arroz e milho, o feijão-da-colônia (Vigna unguiculata (L.) Walp), o maxixe (Cucumis anguria L.), o cará (Dioscorea sp.), a melancia (Citrullus vulgaris Schrad.), o jerimum (Cucurbita sp.), a batata-doce (Ipomea batatas L.), o ária (Maranta lutea Jacq.) e o abacaxi (Ananas comosus (L.) Merril), além da macaxeira (Manihot utilissima Crantz) e da mandiucaba.

Os sítios são pomares distantes das casas da vila, constituídos por consórcios de plantas perenes úteis que geralmente sucedem os roçados, com predominância de fruteiras. Estes agroecossistemas possuem equivalentes estruturais nos quintais domésticos que circundam as residências, denominados 
localmente de "terreiros". A distinção entre sítios e terreiros não é simples, uma vez que as adjacências das casas de forno ou "retiros" podem ser cultivadas com espécies perenes úteis também, o que configura uma espécie de quintal destas "moradas" provisórias. Estes locais são comumente afastados da vila, embora os consórcios de espécies vegetais aí presentes não se originem obrigatoriamente da introdução de espécies perenes em roçados. No âmbito do presente estudo, assume-se que os sítios são os pomares afastados da vila e os terreiros são os quintais domésticos, embora os sítios possam estar também nos terreiros, o que permite supor que as pessoas utilizem ambos os termos indiscriminadamente ${ }^{1}$. De forma geral, nos sítios e terreiros predominam espécies de grande valor econômico e plantio amplamente disseminado, como pupunha (Bactris gasipaes Kunth), banana (Musa sp.), abacate (Persea americana Mill.), limão (Citrus limon (L.) Burn.), laranja (Citrus sinensis (L.) Osbeck), manga (Mangifera indica L.), taperebá (Spondias mombin L.), caju (Anacardium occidentale L.), mamão (Carica papaya L.), cupuaçu (Theobroma grandiflorum (Willd. Ex Spreng.) Schum.) e açaí, entre outras. Além destas, o tucumã-açu ou jabarana, o bacuri (Platonia insignis Mart.) e outras espécies vegetais silvestres comestíveis, coletadas para autoconsumo ou comercialização, também são comumente encontrados.

O jabarana e o bacuri, abundantes na cobertura vegetal nativa, têm sido sistematicamente introduzidos nas áreas dos sítios e nos terreiros, seja por meio de plantio premeditado ou como consequência da ocupação de espaços com edificações rústicas como as casas de forno, também chamadas de retiros, locais para onde convergem fontes de germoplasma de inúmeras espécies. Entretanto, toda esta agrobiodiversidade ainda coexiste com outras espécies, fruteiras, medicinais, madeireiras ou fornecedoras de utensílios domésticos, a exemplo da cuieira.

Desta forma, espécies silvestres frutíferas podem ser encontradas próximas às casas (terreiros) ou mais distantes (nos sítios) por inúmeros motivos: i) alguns indivíduos já estavam presentes e foram preservados durante o processo de limpeza; ii) alguns indivíduos foram plantados "de semente", premeditadamente; iii) alguns indivíduos foram simplesmente "zelados" após a rebrota que sucede a queima destinada à limpeza do terreno para construção ou à implantação de roçados; e iv) frutos foram trazidos para utilização na alimentação e o acúmulo de sementes nas adjacências permitiu que alguns indivíduos germinassem e "vingassem".

\footnotetext{
1 "Sítios" são plantios de árvores frutíferas perenes, de forma que se pode entender que eles estão presentes nos quintais da vila também. Ao mesmo tempo, as casas de forno ou tapiris, "moradas" provisórias distantes da vila, possuem "terreiros" também, nos quais se encontram inúmeras espécies frutíferas perenes.
}

Novos Cadernos NAEA, v. 16, n. 1, Suplemento, p. 181-201, jun. 2013 
O trabalho do extrativismo não atrapalha o da agricultura, pelo contrário, eles são complementares. "A gente [eu e meu marido] prefere trabalhar no roçado pela manhã e apanhar as frutas pela tarde, que daí trabalha na sombra quando o sol está forte." Estas palavras, proferidas por uma das moradoras, remetem à conclusão de Lévi-Strauss (1997), para quem a exploração da farta variedade de alimentos silvestres e a agricultura incipiente tenderam antes à associação do que à exclusão mútua em toda a América do Sul.

Neste contexto, os sítios e terreiros nos parecem emblemáticos do modo de vida da comunidade, porque é neles que desaparece a já tênue linha que separa a agricultura do extrativismo. Produtores que lançam mão de inúmeras estratégias de sobrevivência, das quais a agricultura e o extrativismo vegetal são as mais importantes, nos sítios e terreiros, realizam o amálgama entre estas duas atividades, transformando em plantios o que a natureza já lhes oferece desde sempre.

\subsection{Os paus de fruta da mata viram plantas}

Árvores frutíferas silvestres às vezes são sacrificadas no momento de botar roçado, mas podem ser resguardadas do fogo também, a exemplo do que registraram Costa e Mitja (2010) para espécies como castanha (Bertholletia excelsa H. \& B.), piquiá (Caryocar villosum (Aubl.) Pres.) e tucumã-açu (Astrocaryum tucuma Martius). Entretanto, após o abandono do roçado ou imediatamente em seguida à queima, ainda nas etapas de plantio, capinas e colheita da mandioca, os "filhos" das fruteiras que "grelam" (brotam) são zelados de forma a substituir a "mãe" abatida. Foram vistos exemplos desta prática com espécies como o piquiá, a bacaba, o bacuri e o tucumã-açu. No caso das duas últimas espécies citadas, a alta densidade de indivíduos nas adjacências da comunidade e nas capoeiras no caminho para os roçados se deve em boa parte a esta prática, aliada possivelmente à resposta positiva aos distúrbios que lhes é peculiar, seja pelo rebrotamento vigoroso das raízes, no caso do bacuri (HOMMA et al; 2007), ou pela resistência à passagem do fogo, em se tratando do tucumã-açu (SANTOS; MITJA, 2011).

Um dos moradores está inclusive formando seu próprio bacurizal a partir do manejo da rebrota intensa subsequente a uma derrubada realizada para a implantação não concretizada de um roçado. Este "canteiro", como alguns moradores o denominam, conta com centenas de pés de bacuri, mesmo após a remoção seletiva de indivíduos empreendida pelo produtor. Em consonância, Homma et al. (2007) afirmam que o manejo desta espécie praticado pelos produtores atualmente, que consideram ainda embrionário, consiste tão somente 
em privilegiar as brotações mais vigorosas procedentes da regeneração, deixandoas em espaçamento aleatório nos roçados abandonados.

Não obstante, existem outras práticas que favorecem o adensamento de algumas espécies silvestres locais. Uma das famílias da comunidade não coleta mais tucumã-açu nativo, porque nas adjacências de sua casa de forno já existem vários indivíduos adultos e produtivos "de planta". No âmbito da sinergia entre floresta e agricultura, as pessoas fazem distinção entre as espécies vegetais silvestres, entendidas como "da natureza" e aquelas cultivadas, denominadas "de planta". Essa última categoria não diz respeito apenas às espécies de domesticação consolidada, mas também àquelas que são trazidas da mata para as proximidades das habitações, semeadas intencionalmente ou simplesmente zeladas quando germinam espontaneamente e, portanto, de alguma forma, cultivadas.

A formação deste tucumanzal doméstico se deu da seguinte maneira: os frutos eram apanhados para consumo na casa de forno, em merendas realizadas no intervalo do trabalho. À medida que os frutos eram consumidos, os caroços eram descartados nas imediações da casa e aí germinaram. Depois de estabelecidas as plantas, algumas foram removidas para evitar o adensamento elevado e outras foram "zeladas", aquelas que apresentaram maior vigor vegetativo: "fui escolhendo as mais bonitas, as mais vistosas pra deixar, as outras, fui tirando".

Desta forma, o tucumã-açu, também denominado jabarana localmente, que vegeta próximo às casas, assim como diversas frutas silvestres cultivadas ou zeladas nos terreiros, constitui-se em objeto de seleção, porque as sementes, tanto as plantadas conscientemente quanto aquelas simplesmente descartadas nas adjacências das edificações, são na maior parte dos casos oriundas de plantas conhecidas pela qualidade dos frutos. Embora ainda ocorra em densas aglomerações nativas na área da reserva, o tucumã-açu é, nos dias de hoje, uma espécie bastante cultivada em Melancial. Neste tocante, as pessoas inclusive acreditam que os frutos mais saborosos são aqueles colhidos de árvores plantadas. De acordo com um morador: "hoje, o sujeito pra ter um jabarana de qualidade, tem que ser plantado mesmo, por isso, hoje tem mais plantado do que nativo". Indivíduos da espécie estão recorrentemente presentes nos terreiros das casas. Em quatro anos, as árvores de jabarana plantadas já estão produzindo, o que, de acordo com os moradores, serve de estímulo ao cultivo. "A gente separa o caroço quando encontra um fruto bom, gostoso. Desse aqui merece plantar".

Estes dados contrastam com aqueles disponíveis na escassa literatura concernente ao tucumã-açu, que acusa a baixa adesão ao cultivo da espécie pelos agricultores amazônicos (ELIAS; FERREIRA; GENTIL, 2006; GENTIL; FERREIRA, 2005). Neste sentido, a difícil e demorada germinação das sementes

Novos Cadernos NAEA, v. 16, n. 1, Suplemento, p. 181-201, jun. 2013 
do tucumã-açu é a característica utilizada para explicar o motivo pelo qual seu cultivo ${ }^{2}$ é inexpressivo (ELIAS; FERREIRA; GENTIL, 2006; GENTIL; FERREIRA, 2005). Não obstante, nenhum dos moradores de Melancial fez menção a tal característica. Para Gentil e Ferreira (2005), a ocorrência do tucumãaçu em sítios e quintais, geralmente encontra-se associada à dispersão natural, à dispersão involuntária feita pelo homem e também à manutenção premeditada de plantas jovens e adultas em áreas sob diferentes usos agrícolas, constatação que encontra ressonância em Melancial.

Nos terreiros, é comum constatar, além da presença do jabarana, a de árvores como o bacuri, a castanha e o piquiá, plantadas pelos moradores. O quintal de um casal da comunidade é bem exemplar nesse sentido: árvores como piquiá, castanheira, bacurizeiro, mari (Poraqueiba sericea Tul.) e tucumã-açu, além da andiroba (Carapa guianensis Aubl.), todas ocorrentes em estado silvestre nas formações vegetais adjacentes, foram plantadas pela mãe do marido há mais de trinta anos, sempre a partir de sementes escolhidas pelo sabor dos frutos, à exceção da andiroba e da castanheira ${ }^{3}$.

Neste sentido, existe inclusive acúmulo em relação ao comportamento de algumas espécies. O piquiá, por exemplo, é reputado como de fácil germinação: "é só encanteirar o caroço que ele grela". De acordo com algumas pessoas, o costume de cultivar espécies silvestres é antigo e decorre do desejo de trazer para perto de casa árvores que forneçam frutos similares àqueles encontrados na mata em uma árvore específica, célebres pelo sabor agradável ou outra característica desejada, tal como tamanho avantajado, teor elevado de gordura ou grande quantidade de polpa.

As árvores da mata que produzem bons frutos recebem nomes próprios, que geralmente fazem referência ao dono do terreno em que se encontram ou ao morador mais próximo, podendo ainda ser batizadas em decorrência de alguma característica específica e distintiva. Um exemplo é o "piquiá do Dama", apelido do morador mais próximo da referida árvore, famosa pelos frutos "massudos, gordos e gostosos", cujas qualidades acarretaram no plantio de inúmeras mudas originadas de suas sementes. Em um dos depoimentos colhidos, o morador diz: "o piquiá do Dama é pai de muitas árvores de piquiá por aî". Esse também é o caso do "bacuri do cipoal", coberto de cipós dos galhos até o chão e famoso pelos frutos "massudos e docinhos", que de acordo com um dos relatos, forneceu

\footnotetext{
Aqui, na acepção estritamente agronômica da palavra.

É fácil entender porque a andiroba não é selecionada: diferentemente das fruteiras, não há uma característica tão marcante que confira distinção a uma árvore em particular, como o sabor de um fruto que é extremamente agradável ao paladar. Não obstante, ninguém fez menção a uma castanheira de castanhas saborosas. É como se toda castanha tivesse o mesmo gosto.
}

Novos Cadernos NAEA, v. 16, n. 1, Suplemento, p. 181-201, jun. 2013 
material de propagação para inúmeras experiências de cultivo em terreiros. Mesmo o bacurizal em formação mencionado anteriormente é originado a partir do "bacuri do Binga", antigo morador do local.

Além do desejo de ter à disposição frutos de qualidade para o consumo (que em ambientes silvestres podem pertencer a outra pessoa), outros fatores parecem condicionar o plantio de espécies frutíferas silvestres, como o depoimento a seguir aponta: "quem gosta, mostra. Se você gostou de uma fruta, você quer levar pra plantar e mostrar pros outros". Essa assertiva permite perceber as pessoas como colecionadoras de plantas, hábito recorrente não só no meio rural, mas também no urbano. Existe uma satisfação proporcionada pelo plantio de espécies úteis (ou não necessariamente), sejam aquelas de cultivo disseminado por amplas extensões geográficas, sejam representantes da vegetação nativa ou oriundas de outras paragens mais distantes. De certa forma, essa satisfação impele as pessoas a trazê-las do "mato" para tornarem-se "plantas".

Outros elementos corroboram essa percepção. Um dos moradores, por exemplo, trouxe o babaçu de Tucuruí para plantar em Melancial e levou o patauá para lá com o mesmo fim, sob encomenda. Algo similar aconteceu com o bacabí (Oenocarpus mapora Karsten), uma espécie próxima da bacaba (Oenocarpus bacaba Mart.), que não ocorre naturalmente na região, mas foi trazida por moradores que visitaram parentes em outras regiões. Moradores de Melancial em visita à comunidade do Castanheiro, à jusante do rio, manifestaram publicamente o interesse, devidamente contemplado pelos anfitriões, em inúmeras mudas de espécies vegetais ornamentais, comestíveis e medicinais ali cultivadas ou espontâneas. Além disso, o miriti não ocorre naturalmente à altura de Melancial, embora seja encontrado em grandes aglomerações nativas no curso baixo do rio Oeiras. Não obstante, existem alguns indivíduos plantados na área da comunidade, ainda que a espécie não seja utilizada localmente ${ }^{4}$.

Outras espécies silvestres comumente plantadas em Melancial incluem ainda a bacaba e a castanha, além de espécies medicinais como a andiroba. O plantio das espécies silvestres pode ser feito por semeadura direta ou pelo transplante de plântulas encontradas embaixo da árvore matriz. A outra forma de cultivo é aquela já relatada, caracterizada pelo zelo de indivíduos nascidos espontaneamente em locais de interesse.

4 Embora a literatura registre inúmeros usos (SANTOS; COELHO-FERREIRA, 2011).

Novos Cadernos NAEA, v. 16, n. 1, Suplemento, p. 181-201, jun. 2013 


\section{CONSIDERAÇÕES FINAIS: DOMESTICAÇÃO INCIPIENTE?}

Clement (1999) conceitua a domesticação de plantas como um processo coevolucionário no qual a seleção de fenótipos empreendida pelos humanos, consciente ou inconsciente, resulta em mudanças nos genótipos de populações de plantas favorecidas, manejadas ou cultivadas, tornando-as mais úteis e melhor adaptadas às intervenções humanas na paisagem. Desta forma, este autor define, em relação ao aludido processo de coevolução entre humanos e plantas, categorias de populações de espécies vegetais que vão desde aquelas que podem ser consideradas silvestres até as plenamente domesticadas (CLEMENT, 2001). No âmbito do presente estudo, além, é claro, das populações silvestres, interessam ainda, dentre as categorias estabelecidas pelo referido autor, as populações incidentalmente coevoluídas e as incipientemente domesticadas. Em decorrência do favorecimento e da seleção empreendidos pelos moradores e descritos no tópico anterior, algumas das espécies observadas em Melancial parecem estar próximas destas categorias, como o bacuri, o tucumã-açu, a bacaba e o piquiá.

Uma população incidentalmente coevoluída é uma população espontânea que se adapta aos ambientes perturbados pelos humanos, com possibilidade de sofrer mudanças genéticas, mas sem seleção ou outro tipo de intervenção, como as ervas daninhas, por exemplo (CLEMENT, 2001). Em alguns casos, o bacuri, o tucumã-açu e a bacaba parecem se comportar assim em Melancial, onde aglomerações dessas espécies se formam depois de derrubadas ou queimadas realizadas pelos moradores com fins diversos. Algumas descrições de como se dá a formação desses adensamentos evidenciam essa característica: "esse imenso tucumanzal que o senhor vê aí por trás da comunidade vem de duas árvores de tucumã, não passava disso. Depois que derrubou e passou o fogo, olha como está".

Outra categoria concebida por Clement (2001) que parece estar representada em Melancial é aquela que engloba as populações incipientemente domesticadas. Para o autor, nesse caso, a intervenção humana já acarreta em pressão de seleção sobre estas populações, mas "o fenótipo médio ainda se encontra dentro da variação encontrada na população silvestre para os caracteres sujeitos à seleção" (CLEMENT, 2001). Em vários depoimentos, emerge o desejo de possuir "plantas" (a acepção local do termo é perfeita aqui) de uma determinada espécie capazes de produzir frutos similares àqueles silvestres apreciados por características como tamanho, sabor e volume de polpa, o que determina a escolha do material de propagação. A variância fenotípica correspondente, apresentada pela parcela da população desta espécie que sofre pressão de seleção por ação humana poderá ser, ou não, menor do que a da parcela silvestre, mas sua variância genética já

Novos Cadernos NAEA, v. 16, n. 1, Suplemento, p. 181-201, jun. 2013 
começou a reduzir (CLEMENT, 2001). Entre as plantas observadas, o piquiá e os já citados bacuri, bacaba e tucumã-açu preenchem requisitos que permitem enquadrá-los nessa categoria.

De forma a evitar controvérsias, vale ressaltar que alguns autores assumem que domesticação e cultivo são processos autônomos que não devem ser confundidos. A partir dessa perspectiva, o cultivo se caracteriza pelos cuidados dispensados à propagação de determinada espécie, e não implica necessariamente na seleção intencional de características desejáveis, o que distingue a domesticação (JORGE, 2004). Ou seja, cultivar espécies não representa um estágio inicial do processo de domesticação, o que, por si só, desautoriza afirmar que ele esteja em curso em Melancial para as espécies anteriormente mencionadas neste tópico.

Entretanto, espécies vegetais silvestres não são apenas cultivadas pelos moradores de Melancial, mas também selecionadas. Exceções são a andiroba e a castanheira, que se diferenciam de outras espécies silvestres cultivadas, à medida que sua propagação por mãos humanas parece não implicar em consequências genéticas para as populações locais da espécie. O material de propagação utilizado pelos moradores, de acordo com os relatos, não é selecionado segundo algum critério específico, como acontece com demais fruteiras.

Em consonância, estudos realizados em outras localidades da Amazônia fornecem indícios semelhantes de que certas práticas favoreçam o adensamento de espécies úteis coletadas na mata e mesmo sua gradativa introdução na paisagem do entorno das casas (MACHADO, 2009), inclusive com consequências genéticas para estas espécies, em alguns casos (KERR; CLEMENT, 1980).

Adicionalmente, as populações incipientemente domesticadas estão ecologicamente adaptadas às paisagens prístinas, promovidas, manejadas e cultivadas $^{5}$ (CLEMENT, 2001), o que parece ser o caso do bacuri, da bacaba, do tucumã-açu, do piquiá e até mesmo da castanha, todos encontrados na mata primária, nas capoeiras e nos sítios e terreiros.

5 A referida classificação de paisagens desenvolvida por Clement (1999; 2001) inclui as seguintes categorias: prístinas são paisagens sem nenhuma manipulação humana do ambiente, nem das populações de plantas ou animais ocorrentes; promovidas são paisagens em que plantas individuais e/ou populações de plantas úteis são favorecidas por meio de eliminação ou poda de algumas plantas competidoras ou da gradativa alteração da cobertura florestal; manejadas são paisagens nas quais a abundância e diversidade de populações de plantas úteis desejadas, favorecidas por meio de práticas que as tornam mais aptas à competição, melhoram seu crescimento e reprodução; cultivadas são paisagens totalmente transformadas pela substituição do ecossistema original através de uma combinação de técnicas que possibilitam o crescimento e reprodução das plantas semeadas. O mesmo autor ainda trata como categorias à parte, as roças/capoeiras e as monoculturas, apesar de ambas apresentarem características que permitem admitir sua inclusão em outras das categorias supracitadas. Em todo caso, roças/capoeiras são paisagens nas quais seres humanos alternam o cultivo e o manejo da sucessão florestal subsequente, cada vez menos intenso; e monoculturas são paisagens cultivadas dominadas por populações monoespecíficas (CLEMENT, 1999; 2001).

Novos Cadernos NAEA, v. 16, n. 1, Suplemento, p. 181-201, jun. 2013 
Por fim, a distinção entre extrativismo e agricultura é tênue em Melancial. Muitas das espécies silvestres úteis são ativamente manipuladas, o que sugere que a dicotomia entre agricultura e ambientes naturais é falsa (BHARUCHA; PRETTYY, 2010). Enquanto coletoras que plantam, as pessoas manipulam, de uma forma ou de outra, as plantas silvestres, e enquanto agricultoras que coletam, manejam o conjunto da paisagem.

Diante do exposto, agrobiodiversidade parece uma definição adequada para essa convergência de estratégias, na medida em que inclui todos os componentes da biodiversidade que têm relevância para a agricultura e a alimentação ${ }^{6}$. Em Melancial, agricultura e manejo de recursos da floresta constituem um amálgama dentro do qual as interações entre ambas as atividades são, de certa forma, mediadas pela alimentação. Se uma definição de agrobiodiversidade que leva em conta todos esses elementos pode ser considerada válida para qualquer situação, em Melancial, a agrobiodiversidade começa, inequivocamente, nas cozinhas e chega até a mata, após passar pelos terreiros, roçados, sítios e capoeiras.

Populações amazônicas vêm também manejando e mesmo diversificando espécies silvestres que fornecem frutas. Manejo com consequências genéticas pode estar sendo realizado por populações humanas em toda a região, assim como práticas nesse sentido podem estar sendo abandonadas sem que a ciência tome conhecimento de que um dia existiram. O exemplo de Melancial evidencia a necessidade de mais pesquisas acerca do tema.

\section{REFERÊNCIAS}

ADAMS, C. As florestas virgens manejadas. Boletim do Museu Paraense Emílio Goeldi, Série Antropologia, Belém, v. 10, n.1, p. 3-20, 1994.

ADAMS, C.; MURRIETA, R. S. S.; NEVES, W. Sociedades caboclas amazônicas: modernidade e invisibilidade. In: ADAMS, C.; MURRIETA, R. S. S.; NEVES, W. (Orgs.). Sociedades caboclas amazônicas: modernidade e invisibilidade. São Paulo: FAPESP; Annablume, 2006. p. 15-32.

ALLEGRETTI, M. H. Políticas para o uso dos recursos naturais renováveis: a região amazônica e as atividades extrativas. In: CLÜSENER-GODT, M.; SACHS, I. (Eds.). Extractivismo na Amazônia Brasileira. Montevidéu: UNESCO, 1996. p. 14-33. Compêndio MAB 18.

\footnotetext{
$5^{\text {a }}$ Conferência das Partes da Convenção sobre Diversidade Biológica, Decisão V/5, Apêndice: O âmbito da biodiversidade agrícola, Nairóbi, 2000. Disponível em: < http://www.mma.gov. br/estruturas/sbf_chm_rbbio/_arquivos/cop5ing_72.pdf>. Acesso em: 2 ago. 2012.
} 
ALMEIDA, A. W. B. Antropologia dos archivos da Amazônia. Rio de Janeiro: Casa 8, Fundação Universidade do Amazonas, 2008. 192p.

ANDERSON, A. B.; POSEY, D. A. Manejo de cerrado pelos índios Kayapó. Boletim do Museu Paraense Emílio Goeldi, Série Botânica, Belém, v. 2, n. 1, p. 77-98, 1985.

ANDERSON, A. B.; POSEY, D. A. Reflorestamento indígena. Ciência Hoje, Rio de Janeiro, v. 12, n. esp., p. 6-12, 1991.

BAHRI, S. Do extrativismo aos sistemas agroflorestais. In: EMPERAIRE, L. (Ed.). A floresta em jogo: o extrativismo na Amazônia central. São Paulo: UNESP; Imprensa Oficial do Estado, 2000. p. 167-176.

BALÉE, W. Cultura na vegetação da Amazônia brasileira. In: NEVES, W. (Org.). Biologia e ecologia humana na Amazônia: avaliação e perspectivas. Belém: Museu Paraense Emílio Goeldi, 1989. p. 95-109. (Coleção Eduardo Galvão)

BHARUCHA, Z.; PRETTY, J. The roles and values of wild foods in agricultural systems. Philosophical Transactions of The Royal Society B, Londres, v. 365, p. 2913-2926, 2010.

BRONDÍZIO, E. S. Intensificação agrícola, identidade econômica e invisibilidade entre pequenos produtores rurais amazônicos: caboclos e colonos numa perspectiva comparada. In: ADAMS, C.; MURRIETA, R. S. S.; NEVES, W. (Orgs.). Sociedades caboclas amazônicas: modernidade e invisibilidade. São Paulo: FAPESP; Annablume, 2006. p. 195-235.

CLEMENT, C. R. Melhoramento de espécies nativas. In: NASS, L. L.; VALOIS, A. C. C.; MELO, I. S.; VALADARES-INGLIS, M. C. (Eds.). Recursos genéticos \& melhoramento - plantas. Rondonópolis: Fundação MT, 2001. p. 423-441.

1492 and the loss of Amazonian crop genetic resources. I. The relation between domestication and human population decline. Economic Botany, Nova Iorque, v. 53, n. 2, p. 188-202, 1999.

COSTA, J. R.; MITJA, D. Uso de recursos vegetais por agricultores familiares de Manacapuru (AM). Acta Amazonica, Manaus, v. 40, n. 1, p. 49-58, 2010.

CUNHA, M. C.; ALMEIDA, M. B. Introdução. In: CUNHA, M. C.; ALMEIDA, M. B. (Orgs.). Enciclopédia da floresta. São Paulo: Companhia das Letras, 2002. Parte 1, p. 11-28. 
$5^{\mathrm{a}}$ CONFERÊNCIA DAS PARTES DA CONVENÇÃO SOBRE DIVERSIDADE BIOLÓGICA, Decisão V/5, Apêndice: O âmbito da biodiversidade agrícola, Nairóbi, 2000. Disponível em: <http://www.mma.gov. br/estruturas/sbf_chm_rbbio/_arquivos/cop5ing_72.pdf $>$. Acesso em: 2 ago. 2012.

DENEVAN, W. M. The Pristine Myth: The Landscape of the Americas in 1492. Annals of the Association of American Geographers, Washington, DC, v. 82, n. 3, p. 369-385, 1992.

DIEGUES, A. C. O mito moderno da natureza intocada. São Paulo: Hucitec; NUPAUB-USP, 2008. 198 p.

DRUMMOND, J. A. O manejo agroflorestal científico como um uso alternativo de recursos naturais na Amazônia Brasileira. Estudos Sociedade e Agricultura, Rio de Janeiro, v. 11, p. 99-133, 1998.

ELIAS, M. E. A.; FERREIRA, A. N.; GENTIL, D. F. O. Emergência de plântulas de tucumã (Astrocaryum aculeatum) em função da posição de semeadura. Acta Amazonica, Manaus, v. 36, n.3, p. 385-388, 2006.

FAO. Interacção do género, da agrobiodiversidade e dos conhecimentos locais ao serviço da segurança alimentar - Manual de formação. Roma: FAO, 2005. 171p.

FRAXE, T. J. P. F.; PEREIRA, H. S.; WITKOSKI, A. C. Comunidades ribeirinhas amazônicas: modos de vida e uso dos recursos naturais. Manaus: EDUA, 2007. 224p.

GENTIL, D. F. O.; FERREIRA, S. A. N. Morfologia da plântula em desenvolvimento de Astrocaryum aculeatum Meyer (Arecaceae). Acta Amazonica, Manaus, v. 35, n. 3, p. 337-342, 2005.

HOMMA, A. K. O. Extrativismo, biodiversidade e biopirataria na Amazônia. Brasília: Embrapa Informação Tecnológica, 2008. 97p. (Texto para Discussão, 27).

Biopirataria na Amazônia: como reduzir os riscos? Amazônia: Ciência \& Desenvolvimento, Belém, v. 1, n. 1, p. 47-60, 2005a.

Amazônia: como aproveitar os benefícios da destruição? Estudos Avançados, São Paulo, v. 19, n. 54, p. 115-135, 2005b. 
Extrativismo vegetal na Amazônia: limites e possibilidades. In: CLÜSENER-GODT, M.; SACHS, I. (Eds.). Extractivismo na Amazônia Brasileira. Montevidéu: UNESCO, 1996. p. 35-60. (Compêndio MAB, 18)

Extrativismo vegetal na Amazônia: limites e oportunidades. Brasília: Embrapa-SPI, 1993. 202p.

Reservas extrativistas: uma opção de desenvolvimento viável para a Amazônia? Pará Desenvolvimento, Belém, v. 25, p. 38-48, 1989.

HOMMA, A. K. O.; MENEZES, A. J. E. A.; MATOS, G. B.; FERREIRA, C. A. P. Manejando a planta e o homem: os bacurizeiros no Nordeste paraense. In: LIMA, M. C. (Org.). Bacuri: agrobiodiversidade. São Luís: IICA, 2007. p. 171-210.

JORGE, M. H. A. A domesticação de plantas nativas do pantanal. Corumbá: Embrapa Pantanal, 2004. 20p. (Embrapa Pantanal. Documentos, 70).

KERR, W. E. Agricultura e seleções genéticas de plantas. In: RIBEIRO, B. G. (Coord.). Suma Etnológica Brasileira, vol. 1: Etnobiologia. Belém: EDUFPA, 1997. p. 181-197.

KERR, W. E.; CLEMENT, C. R. Práticas agrícolas de consequências genéticas que possibilitaram aos índios da Amazônia uma melhor adaptação às condições ecológicas da região. Acta Amazonica, Manaus, v. 10, n. 2, p. 251-261, 1980.

LESCURE, J. P.; PINTON, F. L'extractivisme: une valorisation contestée de l'ecosystème forestier. In: HLADIK, C. M. et al. (Orgs.). L'Alimentation em forêt tropicale, vol. II. Paris: UNESCO, 1996. p. 1209- 1218.

LESCURE, J. P.; PINTON, F.; EMPERAIRE, L. O povo e os produtos florestais na Amazônia Central: uma abordagem multidisciplinar do extrativismo. In: CLÜSENER-GODT, M.; SACHS, I. (Eds.). Extractivismo na Amazônia Brasileira. Montevidéu: UNESCO, 1996. p. 62-94. (Compêndio MAB, 18).

LÉVI-STRAUSS, C. O uso das plantas silvestres da América do Sul tropical. In: RIBEIRO, B. G. (Coord.). Suma Etnológica Brasileira, v. 1: Etnobiologia. Belém: EDUFPA, 1997. p. 19-42.

MACHADO, A. T.; SANTILLI, J.; MAGALHÃES, R. A agrobiodiversidade com enfoque agroecológico: implicações conceituais e jurídicas. Brasília: Embrapa Informação Tecnológica, 2008.98 p. (Texto para Discussão, 34) 
MACHADO, J. S. Arqueologia e história nas construções de continuidade na Amazônia. Boletim do Museu Paraense Emílio Goeldi, Ciências Humanas, Belém, v. 4, n. 1, p. 57-70, 2009.

PEDROSO JÚNIOR, N. N.; MURRIETA, R. S. S.; ADAMS, C. A agricultura de corte e queima: um sistema em transformação. Boletim do Museu Paraense Emílio Goeldi, Ciências Humanas, Belém, v. 3, n. 2, p. 153-174, 2008.

PEREIRA, J. R.; LITTLE, P. E. DRPE - Diagnóstico Rural Participativo Emancipador. Viçosa: UFV, 2000. 17p. Não publicado

POSEY, D. A. Manejo da floresta secundária, capoeiras, campos e cerrados (Kayapó). In: RIBEIRO, B. G. (Coord.). Suma Etnológica Brasileira, v. 1: Etnobiologia. Petrópolis: Vozes, 1986. p. 173-188.

RÊGO, J. F. Amazônia: do extrativismo ao neoextrativismo. Ciência Hoje, Rio de Janeiro, v. 25, n. 147, p. 62-65, 1999.

RIBEIRO, D. Uirá sai à procura de Deus. Rio de Janeiro: Paz e Terra, 1974. 178p.

SANTILLI, J. Agrobiodiversidade e direito dos agricultores. São Paulo: Peirópolis, 2009. 520p.

SANTOS, A. M.; MITJA, D. Pastagens arborizadas no Projeto de Assentamento Benfica, município de Itupiranga, Pará, Brasil. Revista Árvore, Viçosa, v. 35, n. 4, p. 919-930, 2011.

SANTOS, R. F.; COELHO-FERREIRA, M. Artefatos de miriti (Mauritia flexuosa L. f.) em Abaetetuba, Pará: da produção à comercialização. Boletim do Museu Paraense Emílio Goeldi Ciências Humanas, Belém, v. 6, n. 3, p. 559-571, 2011.

STELlA, A.; KAGEYAMA, P. Y.; NODARI, R. Políticas públicas para a agrobiodiversidade. In: STELLA, A.; KAGEYAMA, P. Y. (Coords.). Agrobiodiversidade e diversidade cultural. Brasília: MMA, 2006. p. 43-58. 
